\title{
Re-Examining the Race to Send Ventilators to Low-Resource Settings
}

\author{
Sreekar Mantena, Khama Rogo, and Thomas F Burke
}

\author{
Introduction \\ Mechanical Ventilation in Different Settings \\ Challenges in Resource-Limited Settings \\ Summary
}

\begin{abstract}
COVID-19 is devastating health systems globally and causing severe ventilator shortages. Since the beginning of the outbreak, the provision and use of ventilators has been a key focus of public discourse. Scientists and engineers from leading universities and companies have rushed to develop low-cost ventilators in hopes of supporting critically ill patients in developing countries. Philanthropists have invested millions in shipping ventilators to low-resource settings, and agencies such as the World Health Organization and the World Bank are prioritizing the purchase of ventilators. While we recognize the humanitarian nature of these efforts, merely shipping ventilators to low-resource environments may not improve outcomes of patients and could potentially cause harm. An ecosystem of considerable technological and human resources is required to support the usage of ventilators within intensive care settings. Medical-grade oxygen supplies, reliable electricity, bioengineering support, and consumables are all needed for ventilators to save lives. However, most ICUs in resource-poor settings do not have access to these resources. Patients on ventilators require continuous monitoring from physicians, nurses, and respiratory therapists skilled in critical care. Health care workers in many low-resource settings are already exceedingly overburdened, and pulling these essential human resources away from other critical patient needs could reduce the overall quality of patient care. When deploying medical devices, it is vital to align the technological intervention with the clinical reality. Low-income settings often will not benefit from resource-intensive equipment, but rather from contextually appropriate devices that meet the unique needs of their health systems. Key words: COVID-19; mechanical ventilation; resource allocation; cost effectiveness; global health; low-resource settings. [Respir Care 2020;65(9):1378-1381. (C) 2020 Daedalus Enterprises]
\end{abstract}

\section{Introduction}

The COVID-19 pandemic is ravaging the world, with $>400,000$ confirmed deaths as of mid-June. Many experts

\footnotetext{
Mr Mantena is affiliated with the Departments of Statistics and Molecular \& Cellular Biology, Harvard University, Cambridge, Massachusetts. Dr Rogo is affiliated with the World Bank Group, Nairobi, Kenya. Dr Burke is affiliated with the Global Health Innovation Laboratory, Department of Emergency Medicine, Massachusetts General Hospital, Boston, Massachusetts. Dr Burke is affiliated with the Harvard Medical School, Boston, Massachusetts and also affiliated with the Harvard T.H. Chan School of Public Health, Boston, Massachusetts.
}

predict that the SARS-CoV-2 virus will continue to spread until either an effective immunization is scaled globally, or until herd immunity is developed. ${ }^{1}$ The strain on health systems may not be reduced for at least the next 18 months. $^{2}$

COVID-19 is a complex, multifaceted disease that, in addition to wreaking havoc in lungs, causes heart, kidney,

The authors have disclosed no conflicts of interests.
Correspondence: Sreekar Mantena. E-mail: sreekar.mantena@gmail.com.

DOI: 10.4187/respcare.08185 
and liver injury, septic shock, and widespread thrombotic events, among other conditions. ${ }^{3}$ Of patients hospitalized due to COVID-19, 5-12\% require advanced respiratory care, including intubation and mechanical ventilation. ${ }^{4}$ While hospitals in developed nations stretch to maximize their ventilator capacity, many low-resource nations such as Chad and South Sudan have $<10$ ventilators in the entire country. ${ }^{5}$

\section{Mechanical Ventilation in Different Settings}

A global race is underway to create inexpensive ventilators for low-resource settings. Thousands of engineers, clinicians, and students from leading academic institutions and corporations are working at a breakneck pace, creating designs for ventilators and constructing prototypes. On the philanthropic front, the World Bank, the World Health Organization, USAID, and private foundations have identified ventilators as priority medical devices for low-resource settings, and they have spent millions of dollars donating ventilators to many countries, including Kenya, Bolivia, and Cambodia. ${ }^{6-10}$

Survival of patients with COVID-19 treated with ventilators in high-income settings is disappointing. Initial reports from high-income countries described mortality rates of 67-81\% among patients treated with invasive mechanical ventilation. ${ }^{11,12}$ More recent mortality rates from the most highly specialized centers in the United States are between $30 \%$ and $40 \% .^{13,14}$ While ICUs in developed nations include comprehensive systems of critical care within which ventilators are nested, very few low-income settings have similar contexts. Critical care in high-income countries includes continuous access to pulse oximeters, cardiac monitors, and other equipment; medications such as antibiotics and vasopressors; and highly trained medical staff, among many other vital components that together comprise quality intensive patient care. However, in most lowincome countries, the infrastructure and resources necessary for delivery of critical care are scarce or nonexistent.

\section{Challenges in Resource-Limited Settings}

A recent study by the Nigerian Ministry of Health revealed that only $55 \%$ of tertiary-level hospitals have functional oxygen delivery equipment, and only $11 \%$ have pulse oximeters. ${ }^{15}$ Similarly, in a 2018 report by the Uganda Ministry of Health, only $38 \%$ of hospitals have sufficient supplies of oxygen, and none of the country's 16 regional or national referral hospitals have enough pulse oximeters to meet patient needs. ${ }^{16}$ Additionally, the World Heath Organization's Surgical Assessment Tool Survey of $>800$ hospitals in low-resource settings found that only $59 \%$ have reliable continuous electricity. ${ }^{17}$ Moreover, a 2018 survey of 42 hospitals across 9 African countries revealed that $>32 \%$ do not have biomedical engineering technicians or maintenance facilities. ${ }^{18}$ Access to and resupply of consumables such as personal protective equipment are also limited in low-income settings. For example, a COVID-19 preparedness report noted that only $50 \%$ of ICUs in Malawi have N95 masks. ${ }^{19}$ A lack of medical-grade oxygen supplies, when combined with electricity shortages, an absence of bioengineering support, and minimal supply lines for consumables, makes the rapid scale-up of ventilators in low-resource settings extremely challenging.

From a human resource perspective, the Italian health system was overwhelmed with COVID-19 cases, despite having 1 doctor per 244 people. ${ }^{20}$ In Africa, this ratio can be a staggering 1 doctor per 10,000 people. ${ }^{20}$ Intensivists and respiratory therapists are necessary to provide intensive care to COVID-19 patients, but they are scarce in lowresource settings. For example, the 2017 World Federation of Societies of Anesthesiologists report revealed that 43 countries globally (37 of which are in Africa) have $<1$ anesthesiologist per 100,000 citizens, a fraction of their recommendation of 4 per 100,000 people. ${ }^{21,22}$ Similarly, a survey in Tanzania revealed that only $20 \%$ of hospitals have physicians trained in adult critical care. ${ }^{23}$ Medical staff in many low-resource settings are already overburdened, and the severe shortage of health care workers is only exacerbated by the rise in COVID-19 cases.

The provision of medical technology for resource-poor settings is often unlikely to improve outcomes and may cause unintended consequences. ${ }^{24,25}$ Deployment of ventilators requires a significant time investment to train health care workers. Additionally, patients on ventilators require intensive monitoring and continuous attention from doctors, nurses, respiratory therapists, pharmacists, bioengineers, and other specialists. Pulling these essential human resources away from other patient needs in systems already exceedingly overstretched has the potential to harm the overall quality of patient care. Health care staff managing ventilators will be diverted away from other patients who need them. Meanwhile, we know that for most patients hospitalized with COVID-19 (ie, 85-95\%) who do not require invasive ventilation, basic interventions such as oxygen administration, nutrition support, and appropriate hydration save lives. ${ }^{3,26}$ A reduction in these essential services could potentially lead to a decrease in available care for other hospitalized patients, and therefore worse outcomes.

This raises the following question: If high-income countries struggle to avert significant morbidity and mortality among ventilated patients with COVID-19, then how do we expect low-resource settings to achieve good outcomes? Under the infrastructure limitations faced by health care workers in low-resource settings, it is likely that survival 


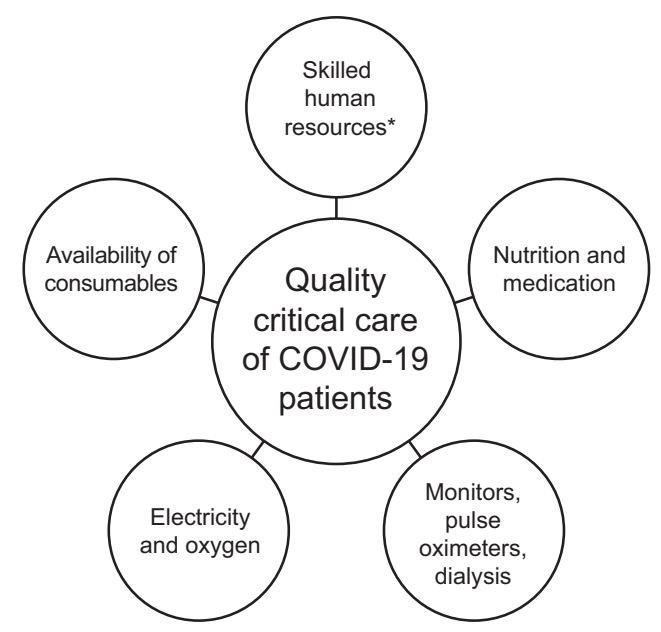

Fig. 1. Ventilator deployment requires an integrated ecosystem of technological and human resources. * Includes ICU nurses, physicians, respiratory therapists, nutritionists, bioengineers, and infection control personnel.

rates for ventilated patients will be low. Furthermore, many low-cost ventilator emergency designs pump air through bag-valve masks and thereby have considerably reduced functionality compared to traditional ventilators. ${ }^{27}$ These devices cannot precisely control the volume, pressure, or humidity of the air being forced into the patient's lungs and therefore may cause barotrauma and exacerbate the lung injury caused by COVID-19. Additionally, many low-cost ventilator designs lack viral filters in the exhalation limb, which means health care staff are at risk from aerosolized viral particles. ${ }^{28}$ Despite the resources invested in deploying ventilators, it is unlikely that sending ventilators to lowresource settings will save lives during the COVID-19 pandemic. Focusing on providing basic provisions such as resuscitation, hydration, noninvasive oxygen support, and other supportive treatment is likely to result in greater benefit to overall patient care.

We applaud the recent efforts of engineers and scientists globally to develop and manufacture low-cost ventilators for resource-poor settings. However, it is important to be informed of the aforementioned challenges before rushing to ship resource-intensive therapies to resource-limited settings. Ventilators, like all medical technologies, need to be embedded within an ecosystem of technological and human resources for them to "do their job" (Fig. 1). The performance of a medical device under ideal conditions in a Boston hospital is very different than in a resource-constrained setting. Lowresource settings benefit most from equipment designed to appropriately serve the unique needs of their health systems.

\section{Summary}

Looking beyond COVID-19, medical technology innovations will remain a key part of advancing the United
Nations Sustainable Development Goals. To bring about the maximum benefit to population health and survival, innovations need to be appropriate for their context and resources allocated for necessary supportive infrastructure..$^{29,30}$

\section{REFERENCES}

1. Randolph HE, Barreiro LB. Herd immunity: understanding COVID19. Immunity 2020;52(5):737-741.

2. Moore KA, Lipsitch M, Barry JM, Osterholm MT. COVID-19: the CIDRAP viewpoint. 2020. Available at: https://www.cidrap.umn.edu/ sites/default/files/public/downloads/cidrap-covid19-viewpoint-part1_ 0.pdf. Accessed May 15, 2020.

3. Berlin DA, Gulick RM, Martinez FJ. Severe Covid-19. N Engl J Med 2020 [Epub ahead of print].

4. Richardson S, Hirsch JS, Narasimhan M, Crawford JM, McGinn T, Davidson KW, et al. Presenting characteristics, comorbidities, and outcomes among 5700 patients hospitalized with COVID-19 in the New York City Area. JAMA 2020;323(20):2052-2059.

5. Nott D. The COVID-19 response for vulnerable people in places affected by conflict and humanitarian crises. Lancet 2020;395(10236): 1532-1533.

6. Reuters. African nations to get ventilators from Jack Ma foundation, stress need for WHO help. 2020. Available at: https://www.reuters. com/article/us-health-coronavirus-africa/african-nations-to-getventilators-from-jack-ma-foundation-stress-need-for-who-helpiduskcn22522d. Accessed May 20, 2020.

7. USAID. The United States provides ventilators to South Africa to battle Covid-19. 2020. Available at: https://www.usaid.gov/south-africa/ press-releases/united-states-provides-ventilators-\%20to-south-africa. Accessed June 10, 2020.

8. World Bank. World Bank facilitates immediate support and resources for the COVID-19 (coronavirus) emergency in Bolivia. 2020. Available at: https://www.worldbank.org/en/news/press-release/ 2020/04/02/el-banco-mundial-facilita-apoyo-y-recursos-inmediatospara-atender-la-emergencia-por-el-covid-19-coronavirus-en-bolivia. Accessed May 20, 2020.

9. World Bank. Kenya COVID-19 Emergency Response Project Procurement Plan. 2020. Available at: http://documents.worldbank. org/curated/en/952941586874418118/kenya-africa-p173820-kenyacovid-19-emergency-response-project-procurement-plan. Accessed May 20, 2020.

10. World Health Organization. WHO, UNDP, World Bank present Ministry of Health with ventilators. 2020. Available at: https://www. who.int/cambodia/news/detail/10-06-2020-who-undp-world-bankpresent-ministry-of-health-with-ventilators. Accessed June 10, 2020.

11. Yang X, Yu Y, Xu J, Shu H, Xia J, Liu H, et al. Clinical course and outcomes of critically ill patients with SARS-CoV-2 pneumonia in Wuhan, China: a single-centered, retrospective, observational study. Lancet Respir Med 2020;8(5):475-481.

12. ICNARC. UK Intensive Care National Audit \& Research Centre COVID-19, Report. 2020. Available at: https://www.icnarc.org/ouraudit/audits/cmp/reports. Accessed May 15, 2020.

13. Argenziano MG, Bruce SL, Slater CL, Tiao JR, Baldwin MR, Barr RG, et al. Characterization and clinical course of 1000 patients with coronavirus disease 2019 in New York: retrospective case series. BMJ 2020;369:m1996.

14. Auld SC, Caridi-Scheible M, Blum JM, Robichaux C, Kraft C, Jacob JT, et al. ICU and ventilator mortality among critically ill adults with coronavirus disease 2019. Crit Care Med 2020 [Epub ahead of print].

15. Federal Republic of Nigeria. National Strategy for the Scale-Up of Medical Oxygen in Health Facilities. 2018. Available at: https:// www.health.gov.ng/doc/National\%20Startegy\%20for\%20Scale-up\% 20of\%20Medical\%20Oxygen.pdf. Accessed Apr 30, 2020. 


\section{Ventilators in Low-Resource Settings}

16. Republic of Uganda. Ministry of Health scale up of medical oxygen in higher level facilities implementation plan. 2018. Available at: http:// library.health.go.ug/sites/default/files/resources/moh\%20national $\% 20$ oxygen $\% 20$ scale $\% 20$ up\%20plan\%206\%20april\%202019.pdf. Accessed April 30, 2020.

17. Meara JG, Leather AJ, Hagander L, Alkire BC, Alonso N, Ameh EA, et al. Global Surgery 2030: evidence and solutions for achieving health, welfare, and economic development. Lancet 2015;386(9993): 569-624.

18. Oosting RM, Wauben L, Groen RS, Dankelman J. Equipment for essential surgical care in 9 countries across Africa: availability, barriers and need for novel design. Health Technol 2019;9(3):269-275.

19. Sonenthal PD, Masiye J, Kasomekera N, Marsh RH, Wroe EB, Scott $\mathrm{KW}$, et al. COVID-19 preparedness in Malawi: a national facilitybased critical care assessment. Lancet Glob Health 2020;8(7):e890e892.

20. World Health Organization. Global Health Observatory data: density of physicians. 2020. Available at: https://www.who.int/gho/health_ workforce/physicians_density/en. Accessed May 15, 2020

21. Kempthorne P, Morriss WW, Mellin-Olsen J, Gore-Booth J. The WFSA Global Anesthesia Workforce Survey. Anesth Analg 2017;125 (3):981-990
22. Davies JI, Vreede E, Onajin-Obembe B, Morriss WW. What is the minimum number of specialist anaesthetists needed in low-income and middle-income countries? BMJ Glob Health 2018;3(6):e001005.

23. Baker T, Lugazia E, Eriksen J, Mwafongo V, Irestedt L, Konrad D. Emergency and critical care services in Tanzania: a survey of ten hospitals. BMC Health Serv Res 2013;13:140.

24. Garrett L. The challenge of global health. Foreign Affairs 2007;86: 14-38.

25. Howitt P, Darzi A, Yang G-Z, Ashrafian H, Atun R, Barlow J, et al. Technologies for global health. The Lancet 2012;380(9840):507535 .

26. Phua J, Weng L, Ling L, Egi M, Lim CM, Divatia JV, et al. Intensive care management of coronavirus disease 2019 (COVID-19): challenges and recommendations. Lancet Respir Med 2020;8(5):506-517.

27. Pearce JM. A review of open source ventilators for COVID-19 and future pandemics. F1000Res 2020;9:218.

28. Dondorp AM, Hayat M, Aryal D, Beane A, Schultz MJ. Respiratory support in COVID-19 patients, with a focus on resource-limited settings. Am J Trop Med Hyg 2020;102(6):1191-1197.

29. Schein M. Seven sins of humanitarian medicine. World J Surg 2010;34(3):471-472.

30. Underwood E. Three reasons humanitarian aid fails. Science 2016. 